\title{
Choose Suitable Wind Turbines for Manjil Wind Power Plant using Monte Carlo Simulation
}

\author{
Saeid Nahi ${ }^{a}$, Seyed Mohammad Hossein Nabavi ${ }^{\text {b }}$ \\ ${ }^{a}$ Islamic Azad University, Ilkhchi Branch, Tabriz, Iran \\ ${ }^{\mathrm{b}}$ Islamic Azad University, Tabriz Branch, Tabriz, Iran
}

\begin{abstract}
Nowadays, power systems, energy generation by wind has been very important. Noting that the production of electrical energy by wind turbines on site is depend on to several factors (such as wind speed and profile site for the turbines, especially off the wind input speed, wind rated speed and wind output speed disconnect) is dependent. On the other hand, there are several different types of turbines in the market. Therefore, selecting a turbine that its capacity could also answer the need for electric consumers the efficiency is high something is important and necessary.

In this context, calculating the amount of wind power production to help optimize overall network, system operation, in determining the parameters of wind power is very important.

In this article, to help calculate the amount of wind power plant, connected to the national network in the region Manjil wind, selecting the best type of turbine and power delivery profile appropriate to the network using Monte Carlo method has been. In this paper, wind speed data from the wind site in Manjil, as minute and during the year has been. Necessary simulations based on Random Numbers Simulation method and repeat, using the software MATLAB and EXCEL has been done.
\end{abstract}

Keywords - Wind turbine, Efficiency, Wind turbine work points, Random Numbers, Reliability

\section{INTRODUCTION}

Creating restructuring in power systems and the need to clean energy, electrical engineers on the Constitution that more attention be new energies. In this light, wind plants widely throughout the world are used [6],[10]. Several ways to improve the performance of wind power plants is presented in various articles [7],[8]. In this context, the most important issues to help calculate the optimal amount of wind power plants [1] and turbine specification is appropriate.

In this article, as wind power plants connected to the network are assumed. Continued influence of some internal parameters of wind turbines [4], including work points, cut in speed, rated speed and cut out speed that related to wind speed and electric power are produced, reviews and have been compared. The exact definition of these concepts below:

- Wind cut in speed $\left(V_{c i}\right)$ : which consists of the lowest wind speed that the turbine will start generating electricity.

- Wind rated speed $\left(V_{r}\right)$ : which consists of wind speed to the point that the turbine reaches its maximum productivity.

- Wind cut out speed ( $V_{c o}$ ): which consists of the Maximum wind speed turbines that can generate electricity.

Done this research in different sections of the article are as follows.
1- Wind turbine modeling in section 2

2- Supplement equivalent to the capacity calculation algorithm presented in section 3

3- Display calculation results can be produced wind turbines in section 4

4- Display and study load trait used in the experiment in section 5

5- How to calculate the reliability and provide the relevant algorithms in section 6

6- Comparative study of the effect and importance of different parameters in the study mentioned in section 7

7- Introducing Types of existing turbines in this research as well as drawing and calculation results in the expression in section 8

\section{8- General conclusion in section 9}

Method presented in this article, we will be able to increase instead of a little wind turbines, with qualitative changes, planning and selection of turbines, the wind zone climate situation, an optimal choice, savings in the number of turbines, resulting in increased reliability system in terms of helping to have the main system.

Wind data from the wind site in Manjil area has been used to measure wind speed as the minutes taken during the year, and programs and computational simulations based on Monte Carlo simulation [5] has been done.

\section{WIND TURBINE MODELING}

Amount of wind turbines to produce electric power from the following equation is calculated.

$$
\begin{aligned}
& P\left(S W_{t}\right)= \\
& \left\{\begin{array}{lr}
0 & 0 \leq S W_{t} \leq V_{c i} \\
\left(A+B+S W_{t}+C \times S W_{t}^{2}\right) \times P_{r} & V_{c i} \leq S W_{t} \leq V_{r} \\
P_{r} & V_{r} \leq S W_{t} \leq V_{c o} \\
0 & S W_{t} \leq V_{c o}
\end{array}\right.
\end{aligned}
$$

In above $S W_{t}, P_{r}, V_{c i}, V_{r}$ and $V_{c o}$ respectively include wind speed, maximum power production, wind cut input speed, Wind Rated Speed, wind cut output speed and the constants A, B, C were related to above through the following equations are calculated.

$$
A=\frac{1}{\left(V_{c i}-V_{r}\right)^{2}}\left\{V_{c i}\left(V_{c i}+V_{r}\right)-4 V_{c i} V_{r}\left[\frac{V_{c i}+V_{r}}{2 V_{r}}\right]^{3}\right\}
$$


(3)

$$
\begin{array}{r}
B=\frac{1}{\left(V_{c i}-V_{r}\right)^{2}}\left\{4\left(V_{c i}+V_{r}\right)\left[\frac{V_{c i}+V_{r}}{2 V_{r}}\right]^{3}-\left(3 V_{c i}+V_{r}\right)\right\} \\
\text { (4) } C=\frac{1}{\left(V_{c i}-V_{r}\right)^{2}}\left\{2-4\left[\frac{V_{c i}+V_{r}}{2 V_{r}}\right]^{3}\right\}
\end{array}
$$

Relationship between Pr, Vci, Vr and Vco chart diagram known as Power Curve (diagrams power - speed) in the figure of (1) are shown.

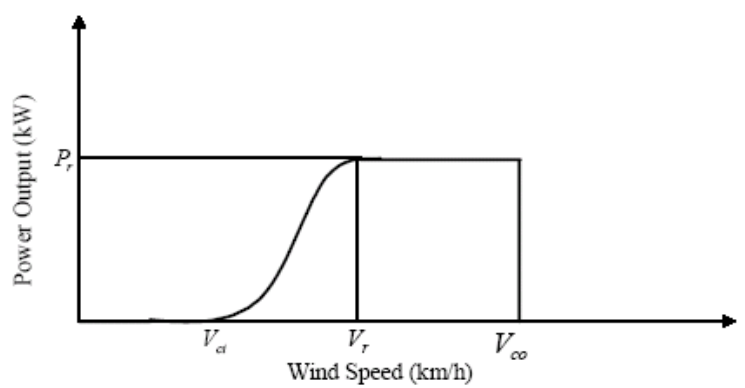

Fig. 1 Changes output power to wind speed in wind generator

\section{EQUIVALENT TO THE CAPACITY CALCULATION ALGORITHM BASED ON RELIABILITY}

Measure of reliability in this study is to measure IPLCC1 index. Equivalent capacity calculation algorithm based on reliability is as follows:

\section{Step 1:}

Collecting, processing and simulating wind speed during the year.

Step 2:

Collecting, processing and simulating changes in load and wind turbines produce throughout the year.

Step 3:

Reliability calculations for various turbines on the market.

Step 4:

Select and compare the results of computations producing on the species of turbines.

Generally, the equivalent of one unit of wind capacity added to the wind farm regime, the following parameters are also dependent [2],[3].

- Units of wind penetration: the ratio of the total amount of installed wind capacity units network. If a unit with a network of wind penetration of $10 \%$ is added, with the capacity equivalent to more than state that the same single network with $20 \%$ penetration can be connected.

- Point of connection: in fact close to the loads and network reliability in the junction unit wind on the equivalent capacity affects.

Algorithms and programming in the section 6-3 draw is as flowchart.

\section{CALCULATION RESULTS CAN BE PRODUCED}

Wind speed profile used in the figures of (2) and (3) a weekly and annually basis are shown.

Wind speed probability distribution are different in shape (4) is drawn from this graph we can notice that the low wind speed $(0 \mathrm{~m} /$ sec) most likely, mid wind speeds (4-14 m/ sec) average possible and more wind speeds $(22 \mathrm{~m} / \mathrm{sec})$ least likely to have occurred during the year.

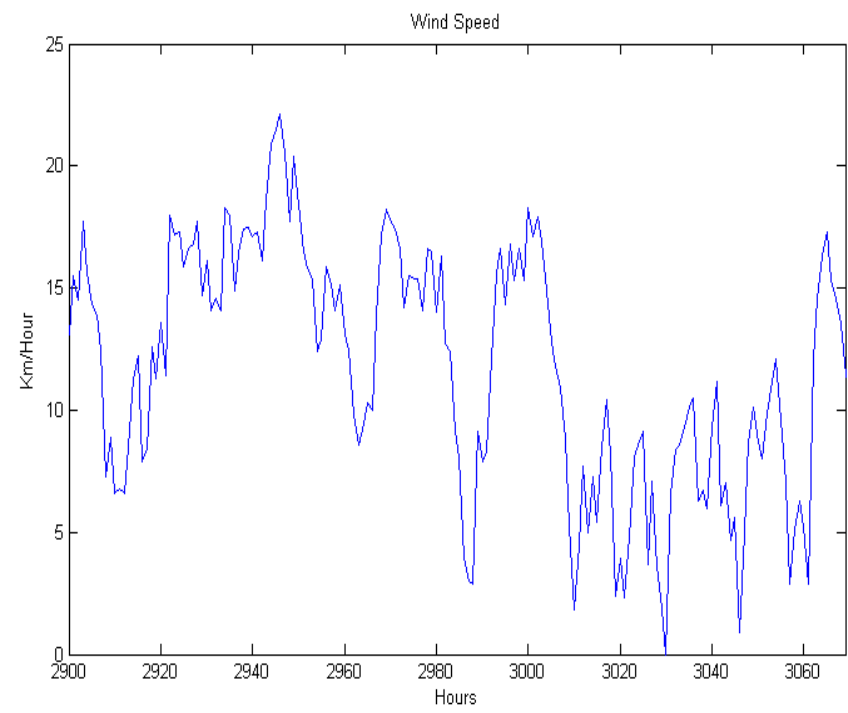

Fig. 2 An example of changes in wind speed during a week in the spring area Manjil

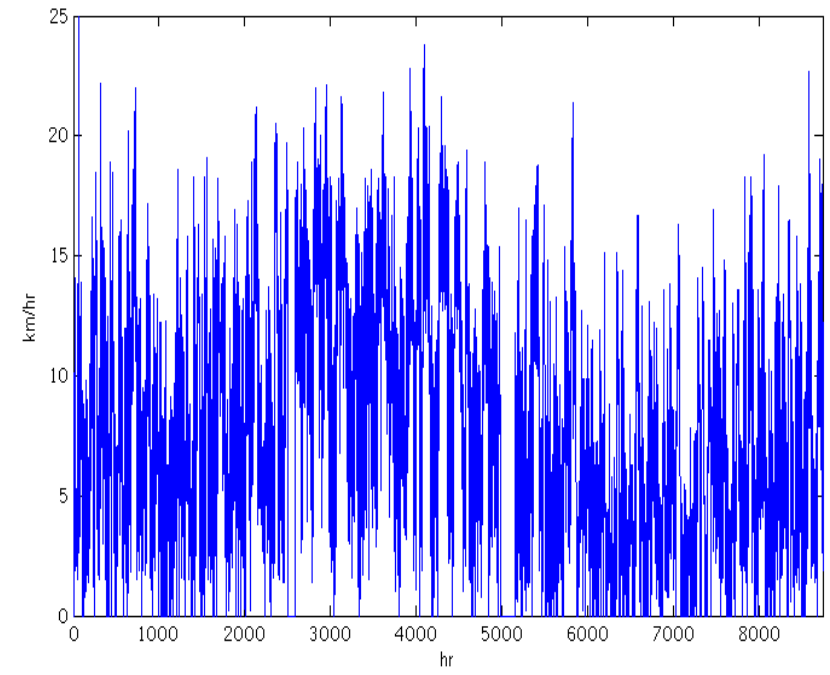

Fig. 3 Changes in wind speed during a year in the region Manjil 


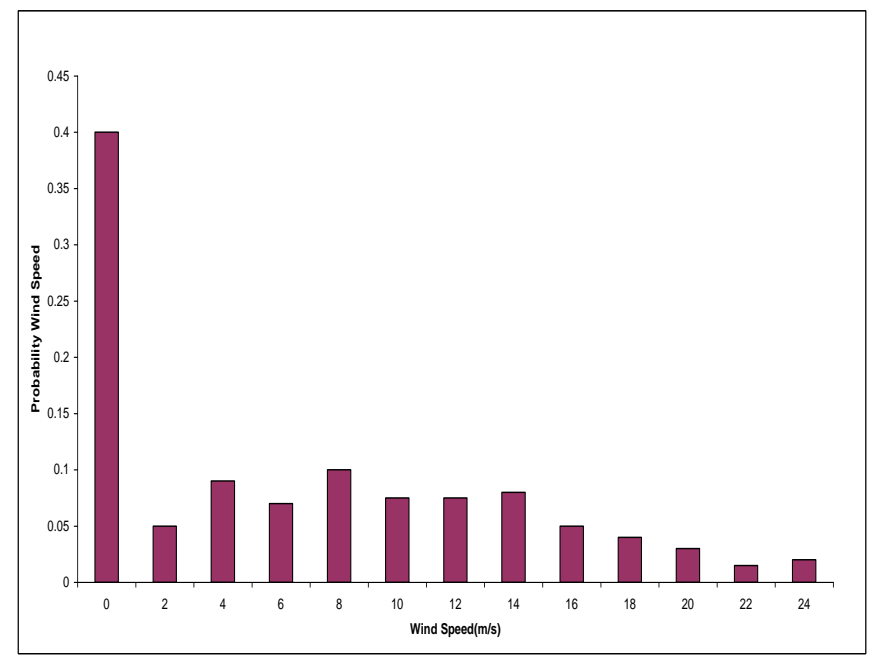

Fig. 4 Annual wind probability distribution in Manjil

In autumn and summer than other seasons we were the lowest mean wind speed and the highest average wind speed we have. In Figure (5) Chances are the color green (autumn), red (summer) and blue (annual average) are plotted.

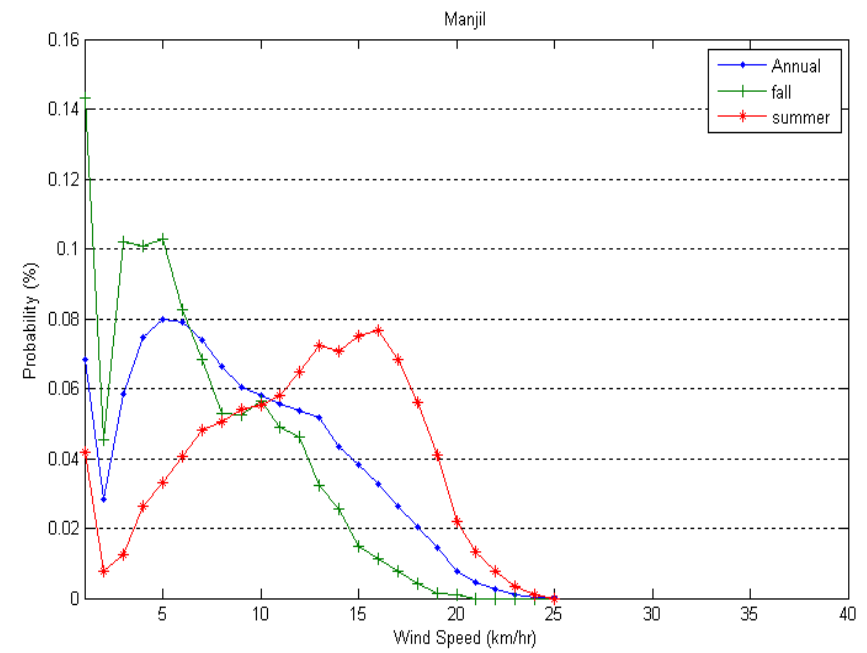

Fig. 5 Wind speed probability autumn, summer and annual regional Manjil

Calculation results can be produced using the relations mentioned in section 2 and applying wind turbines in the region Manjil 660kW (type $\mathrm{H}$ mentioned in table (4)) as an example in the figure of (6) and (7) calculation are shown.

As can be seen in the measurements of wind speed and consequently the production of electrical energy calculations as a minute during the year has been made.

\section{PROFILE OF LOADS USED IN THE TEST}

Load measurements Precision is a hourly during the year has been made. In the figures of (8) and (9) weekly and annual basis is shown.

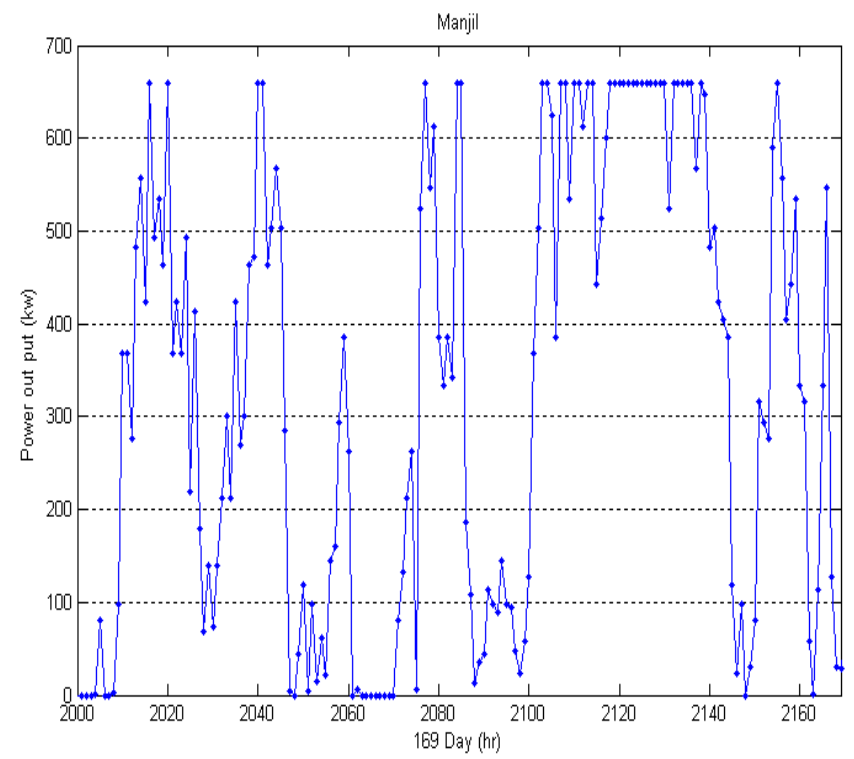

Fig. 6 An example of changes in turbine electric power output during a sample week Manjil area

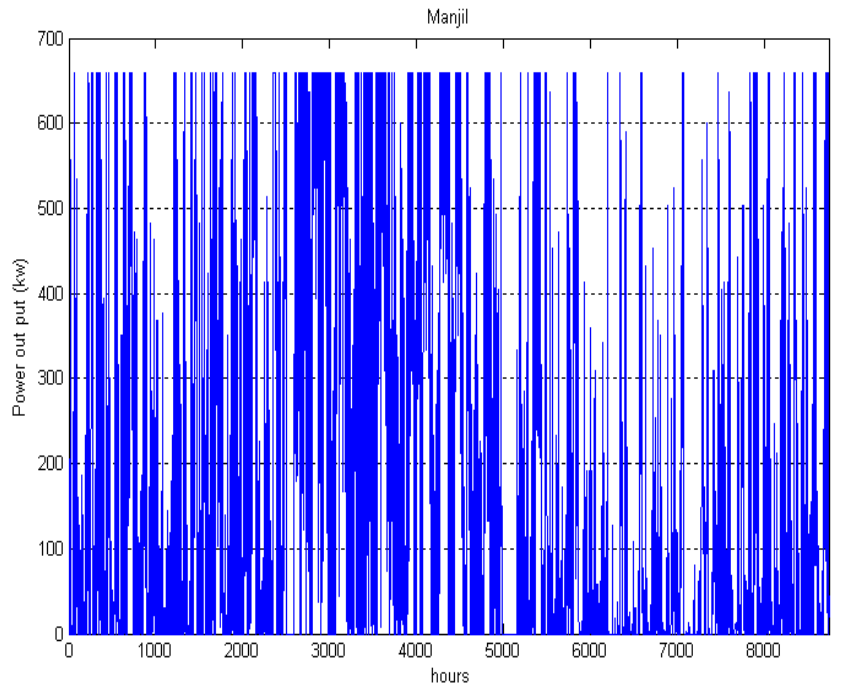

Fig. 7 Changes in electric power output of turbines in one year Manjil area 


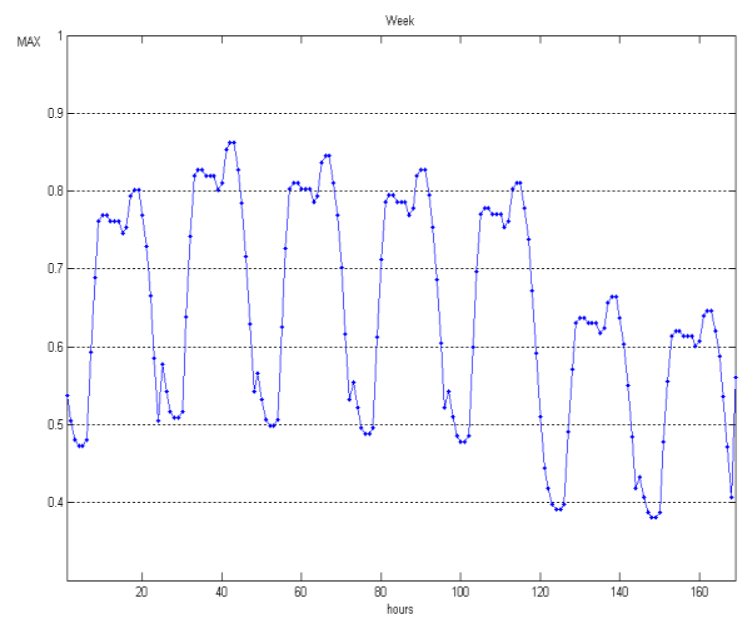

Fig. 8 An example of load changes in during a week

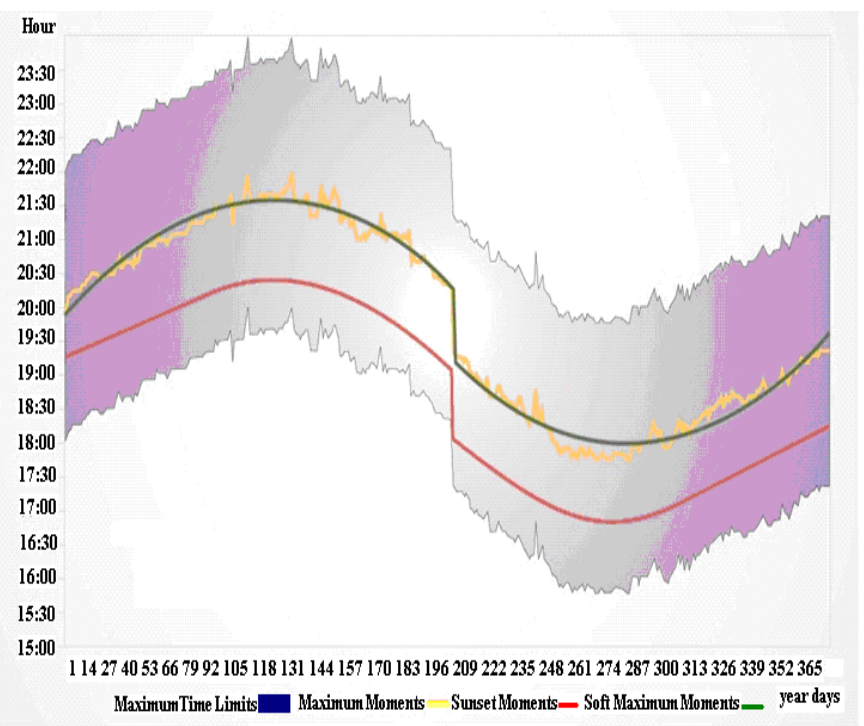

Fig. 9 load Changes in during the year

Study with Iran will be at these comments made at the highest consumption in summer mid day hours and the lowest median intake at other seasons and at mid night hours occur.

Chart load changes at 24 hours in spring (green), summer (orange), autumn (brown) and winter (blue) in the figure of (10) is plotted.

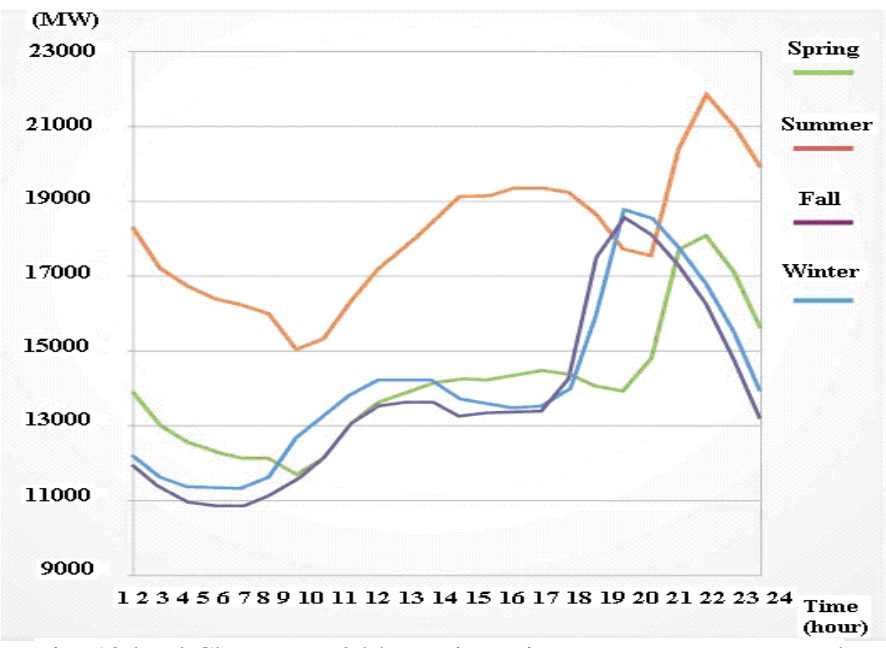

Fig. 10 load Changes at 24 hours in spring, summer, autumn and winter in Iran

\section{RELIABILITY CALCULATION METHOD}

This section details the calculation method has been reliable.

\section{A. Monte Carlo simulation method}

Using information about song damage $\lambda$ and song repair $\mu$ each unit units status for one year is determined.

$T T F_{i}=-\operatorname{Ln}(U) / \lambda_{\mathrm{i}}$

$T T R_{i}=-\operatorname{Ln}(U) / \mu_{\mathrm{i}}$

$T T F$

${ }^{i}$ : Long waiting time for unit $i$ is a failure.

$T T R$

: Long waiting time for unit $i$ is repaired.

$U$ : Uniform random number between zero to one

Beginning in the simulation all units is active. Producing uniform random number will be determined by $T T F_{i}$ units, passed with the time unit is removed from the circuit. To determine the expected repair time production $T T R_{i}$ random number will be determined by that time passed with this unit is back on the circuit. The process according to Figure (11) where the unit status during the year (8760 hours) simulation will be continued.

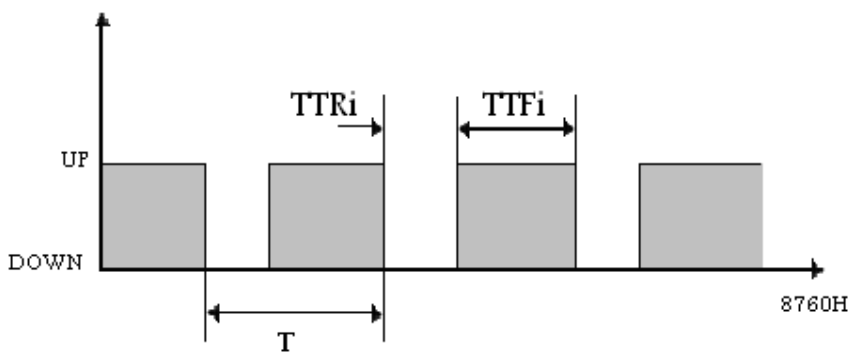

Fig. 11 Status modeling unit i during the year

B. To help calculate the index of wind power plants to nationwide network (IPLCC)

In this paper the method for calculating the reliability index is used Based on the use of daily load curve, which is used daily load curve changes and determine output random power and compare it using 
the repeated random numbers according to figure (12) values we have calculated the reliability.

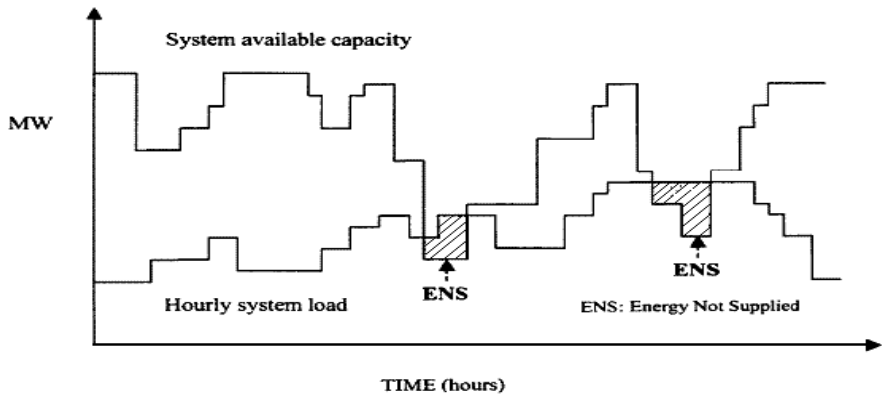

Fig. 12 View changes of load and production

In other words, the process of calculation are as follows:

Step 1: Random production and mapping them out on the possibility of a variable-capacity production units, which represents another capacity available on that day or hour (in exchange for specified maximum load) is obtained.

Step 2: When comparing this value with the load requested by the network capacity if the amount is less than specified load will produce a loss otherwise at this stage (days or hours) will not lack of production. Defined a number of reliability indices used are listed below:

$P L C C_{2:}$ The maximum load that the system provides (MW).

$I P L C C_{3:}$ Maximum load that the production system to help the original system helps and is effective (MW).

The index of relationship

$I P L C C=P L C C_{\text {new }}-P L C C_{\text {orig }}$

Is obtained. Where:

PLCC help of a new production system provides. (MW)

$P L C C$ orig : Maximum load that the main production system, without new production system provides. (MW)

$F O R_{4:}$ Probability of exiting capacity wind turbines

Profile $660 \mathrm{~kW}$ turbines power used in test as follows:

$$
F O R=0.04
$$

$V_{\text {CutIn }}=4 \mathrm{~km} / \mathrm{hr}$

$V_{\text {RatedSpeed }}=15 \mathrm{~km} / \mathrm{hr}$

$V_{\text {CutOut }}=25 \mathrm{~km} / \mathrm{hr}$

\section{Simulation Algorithm}

${ }^{2}$ Peak Load Carrying Capability

${ }^{3}$ Incremental Peak Load Carrying Capability

${ }^{4}$ Forced Outage Rate
Simulation algorithm in Figure (13) is plotted. In this algorithm the amount of wind power to help the national network is calculated.

Definition algorithm variables Next page are as follows:

$\bullet n$ : number of wind turbines in wind power plant

- m: Number of test

- $\mathrm{k}$ : Number of tests during the year

-U: Random number in the relevant period specified

-Pi: Turbine power production per unit time

- FOR: Failure probability of single

- PLCCOrig: Power Production Network

- PLoad: Load requested by the network

- Ps: Differences the load demand with the production network

-PLCCNew: Total electric power production in wind plant

-IPLCC: Wind power production delivered to the national network

Calculation process in various sectors are as follows:

Step 1:

A - Receive annual wind information (SWt) according figure (3)

B - Calculating turbines manufactured can be without regard to possible failures during the year $(\mathrm{P}(\mathrm{SWt}))$ using the relationship (1) and Figure (7)

C - Receive annual load information on the network (PLoad) and production information on the network can be a normal annual production (PLCCOrig) according figure (9)

Step 2:

A - Generate random numbers for the records on the annual wind production in the Monte Carlo method (U)

B - Mapping random number on the annual production of wind and find the moment wind turbine production $(\mathrm{Pi})$

Step 3:

A - Calculated failure probability of turbine (FORi) and if damaged to calculate the repair time and zero turbine production $(\mathrm{Pi}=0)$

B - Add total production of turbines and return to Step 2 to the total number of turbines $(i=n)$

Step 4:

A - Calculation of load demand on the network (Ps) by subtracting the normal load of national network production.

B - Calculate the effective wind power plant helps to the network in the test number of $\mathrm{j}$ (IPLCCj)

Step 5:

A - Advance time to load (PLoad) and power production network (PLCCOrig) to consider the new situation and produced at the Global Network

B - Back to step 2 and repeat the process to end the year $(k=8760)$

Step 6:

A - Tests performed many times $(j=m)$ 
B - Average total catch results help to calculate the exact and true (IPLCC)

In addition to the above characteristics drawn to the following algorithm can also be noted.

1 - When the production network (PLCCOrig) is responsive to the needs of electrical grid (PLoad) wind power production is not calculated.

2 - Based on the total power production of wind power turbines (PLCCNew) account total turbines (n) will be.

3 - Likely out of the repair time and individual capacity turbines (FORi) in operation during the simulation will be considered.

4 - To increase accuracy and minimize the deviation of test results, the whole process simulation of the high frequency of about several million times by high speed computer is done, then the results mean is taken.

\section{CALCUlATE THE SIGNIFICANCE OF EACH OF THE WORK POINTS IN WIND TURBINES IN THE WINDY AREA}

\section{A. METHODS AND RESULTS OF CALCULATIONS}

To evaluate the importance of three work points in the turbine (Vci, $\mathrm{Vr}, \mathrm{Vco}$ ) values on a sample $660 \mathrm{~kW}$ turbine ( $\mathrm{H}$ type listed in Table 4) we change the program to assess the efficiency written, the sensitivity and the importance of each explore.

How it work point is to test changes in an operating point, other types of the work points are considered fixed.

In this context results auxiliary production calculations were expressed in Tables 1 to 3 .

TABLE I

TOTAL AID WIND TURBINES TO THE NETWORK PER CHANGE IN THE TURBINES CUT IN SPEED WORK POINT

\begin{tabular}{ccccccc}
\hline \hline $\begin{array}{c}\mathrm{V}_{\text {Cut In }} \\
(\mathrm{km} / \mathrm{hr})\end{array}$ & 3 & 4 & 5 & 6 & 7 & 8 \\
\hline $\begin{array}{c}\text { IPLCC } \\
(\mathrm{MW})\end{array}$ & 12.4 & 12.3 & 11.8 & 11.2 & 10.8 & 10.2 \\
\hline \hline
\end{tabular}

TABLE II

TOTAL AID WIND TURBINES TO THE NETWORK PER CHANGE IN THE TURBINES RATED SPEED WORK POINT

\begin{tabular}{ccccccc}
\hline \hline $\begin{array}{c}\mathrm{V}_{\text {Rated }} \\
\begin{array}{c}\text { Speed } \\
(\mathrm{km} / \mathrm{hr})\end{array}\end{array}$ & 13 & 14 & 15 & 16 & 17 & 18 \\
\hline $\begin{array}{c}\text { IPLCC } \\
(\mathrm{MW})\end{array}$ & 13.7 & 13 & 12.3 & 10.4 & 9.7 & 9.1 \\
\hline \hline
\end{tabular}

TABLE III

TOTAL AID WIND TURBINES TO THE NETWORK PER CHANGE IN THE TURBINES CUT OUT SPEED WORK POINT

\begin{tabular}{cccc}
\hline \hline $\begin{array}{r}\mathrm{V}_{\text {Cut Out }} \\
(\mathrm{km} / \mathrm{hr})\end{array}$ & 20 & 25 & UP 25 \\
\hline $\begin{array}{r}\text { IPLCC } \\
(\mathrm{MW})\end{array}$ & 11.8 & 12.3 & 12.5 \\
\hline \hline
\end{tabular}

\section{B. SURVEY AND COMPARISION OF THE EFFECT CHANGE WIND TURBINE WORK POINTS IN SYSTEM RELIABILITY}

According to the results obtained in section (7-A) as in Figure (14) is observed due to the presence of wind speeds in most cases in low and medium, respectively, for the region in terms of Manjil and help increase network efficiency According to the original status of the wind speed, the following work points in order wind turbines more important role in the production system and have increased reliability.

$$
\mathrm{V}_{\text {Rated Speed }}>\mathrm{V}_{\text {Cut Input }}>\mathrm{V}_{\text {Cut Output }}
$$

So after, It is better consider in buying wind turbines to characterized by the influence of increased production in the electric wind region is connected to the national network. 


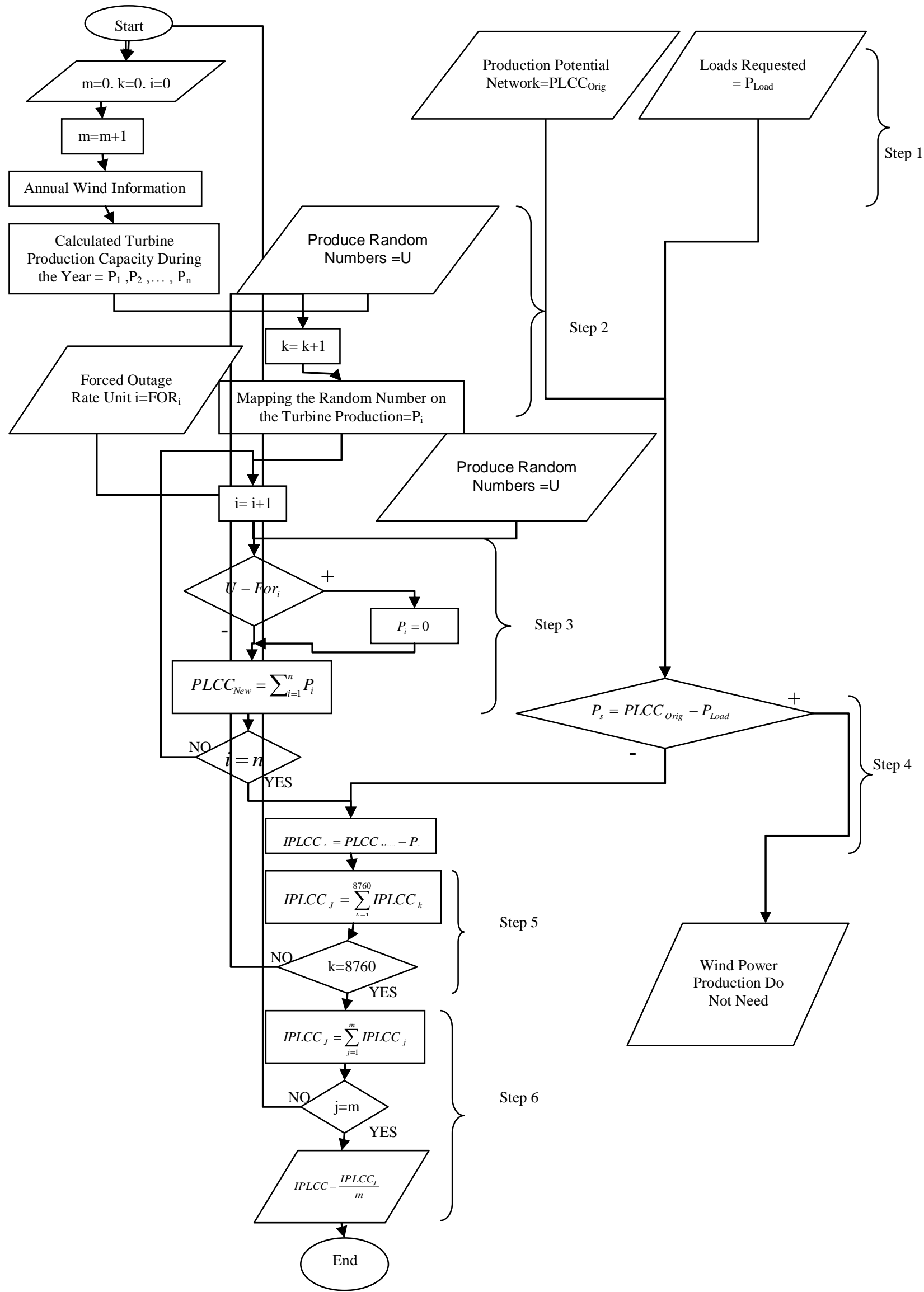

Fig. 13 Algorithm to help calculate the index of wind power to national grid (IPLCC) 


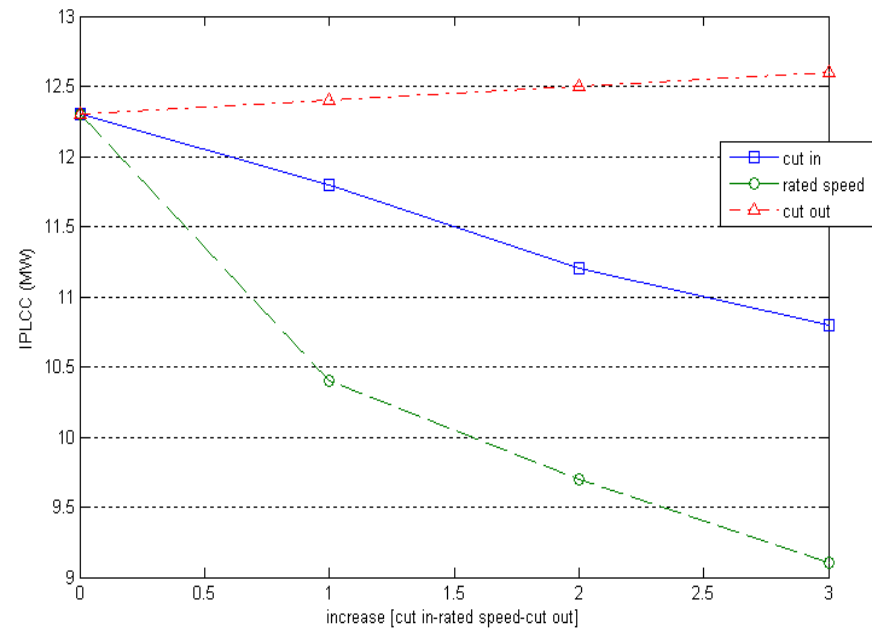

Fig. 14 Comparison of increase in specific work points cut in, rated speed and cut out the turbines on the reliability index IPLCC

\section{TESTED IN WIND TURBINE TYPES IN THE WINDY AREA}

One of the important issues in the classroom and choice wind turbines, turbine performance review capabilities in terms of confidence indicators is expected. We here in the reliability indices of the eight types of turbines with the following features will examine:

- Maximum production capacity: $\mathrm{P}_{\mathrm{r}}=200 \mathrm{~kW}$ to $900 \mathrm{~kW}$

- $\quad$ Probability out of production capacity: $\mathrm{FOR}=0.04$

- $\quad$ Speed limits of working points: $\mathrm{V}_{\mathrm{Cut} I n}=3$ to $6(\mathrm{~km} / \mathrm{hr})$, $\mathrm{V}_{\text {Rated Speed }}=8$ to $15(\mathrm{~km} / \mathrm{hr})$ and $\mathrm{V}_{\text {Cut Out }}=17$ to $32(\mathrm{~km} /$ $\mathrm{hr})$

- $\quad$ and terms of class and size include high-power turbines and large size $(\mathrm{E}, \mathrm{F})$, medium power turbines and medium size $(\mathrm{H}, \mathrm{G}, \mathrm{D})$ and low-power turbines and small size (A, B, C ) As shown in Table 4 in terms of geographic area of Iran Manjil put testing and evaluation. Number of wind turbines are 100 .

TABLE IV

\begin{tabular}{ccccc} 
PROFILE LOCATIONS DO WIND TURBINES USED IN THE TEST \\
\hline \hline Type & $\begin{array}{c}\text { Rated } \\
\text { Power } \\
(\mathrm{kW})\end{array}$ & $\begin{array}{c}\mathrm{V}_{\text {Cut In }} \\
(\mathrm{km} / \mathrm{h})\end{array}$ & $\begin{array}{c}\mathrm{V}_{\text {Rated }} \\
\text { Speed } \\
(\mathrm{km} / \mathrm{h})\end{array}$ & $\begin{array}{c}\mathrm{V}_{\text {Cut Out }} \\
(\mathrm{km} / \mathrm{h})\end{array}$ \\
\hline $\mathrm{A}$ & 225 & 4 & 13 & 26 \\
$\mathrm{~B}$ & 112.5 & 4 & 12 & 32 \\
$\mathrm{C}$ & 112.5 & 3 & 13 & 21 \\
$\mathrm{D}$ & 450 & 5 & 9 & 17 \\
$\mathrm{E}$ & 900 & 6 & 15 & 24 \\
$\mathrm{~F}$ & 900 & 4 & 10 & 30 \\
$\mathrm{G}$ & 450 & 5 & 8 & 30 \\
$\mathrm{H}$ & 660 & 4 & 15 & 25 \\
\hline \hline
\end{tabular}

After the conditions imposed the regional on the wind turbine types mentioned in Table 4, the result of original wind systems to computing to help grid in the figure (15) is plotted.

It is explained by computer simulation of the Pentium 4 and the number of repetitions is three million.

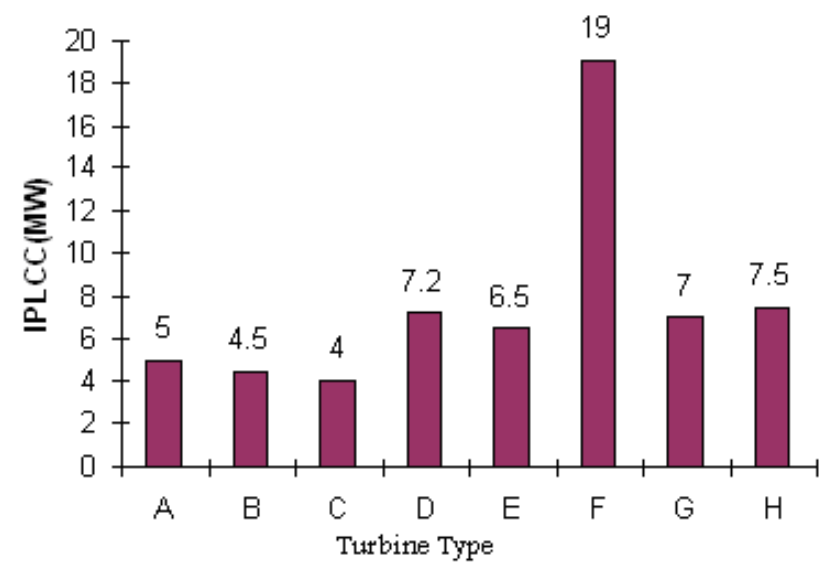

Fig. 15 Calculation results IPLCC (helping wind turbines to the main network), types of wind turbines in the area of Manjil

According to the chart (15) results that are deduced are:

1 - In terms of helping to meet the system load demand IPLCC, 900 $\mathrm{kW}$ turbine type $\mathrm{F}$ is the best result.

2 - Turbine type $\mathrm{D}(450 \mathrm{~kW})$ with less power than the turbine type $\mathrm{E}$ (with power $900 \mathrm{~kW}$ ), would have power equal to $700 \mathrm{~W}$ higher than the turbine type $\mathrm{E}$ to deliver. The selected turbine type $\mathrm{D}$ in addition to producing more power than saving economy, repair maintenance, size, and is ....

3 - Turbine Type B, because a higher speed (VCut Out ) is high could deliver power near turbine type A that is greater than type B to the network.

4 - In terms of wind turbines to help network among the types of turbines in each class (high-power turbines and large-size (E, F), medium-power turbines and medium-size $(\mathrm{H}, \mathrm{G}, \mathrm{D})$ and small-power turbines and low-size (A, B, C)) Turbine type F, D, A was the best result.

And more explanation about the results column chart figure (15) in the results come.

\section{CONCLUSIONS}

In this article, using Monte Carlo simulation to calculate the wind system to help the national network (IPLCC) first receive annual wind information, the annual loads demand and the normal production of national network in the region near the Iranian Manjil examine. And then using computational methods mentioned in section 2 to calculate the production capacity of wind turbines on wind speed and then examine the methods and algorithms presented in Section 6 and considering the failure probability and time turbines required for the circuit back to help calculate the amount of wind power to national grid per year examine turbine types.

Important indicators of wind turbines in this study were effective included: 1 - Maximum turbines capacity power production (Pr), 2 Wind cut input speed (VCut In), 3 - Wind rated speed (VRated Speed), 4 - wind cut output speed (VCut Out)

The number of results in this study can be expressed briefly include:

1 - Due to the presence of wind speeds in most cases at low and medium, respectively Manjil area in terms of efficiency and help to main networks according to the status of wind speed, the following work points in order to wind turbines to produce a more important role have increased reliability of system. 


\section{VRated Speed $>$ VCut In> VCut Out}

2 - With this method we can between the turbines of a class that features close to each other have the best turbine convenient choose for example turbines type A, D and F of Table 4, compared to other turbines like their could be more to deliver national network.

3 - With this method we can find some turbines that despite having less power and prices cheaper in some cases more power from turbines with the power of a rate larger and cost more to produce for example the turbine poor and low-cost type $\mathrm{D}$ could deliver power to the national network more than the turbine type $\mathrm{E}$, which is larger and more expensive in the region corresponding antibody.

4 - We recognize the number of reasons which can reduce or increase production systems related to the parameters investigated in this study.

5 - And could, without increasing the number of wind turbines is just help them with regulate work points turbines to increase the global network.

In other words, the method presented in this article we can wind turbines instead of increasing slightly with changes in quality, and select the best set of turbines with regard to regional atmospheric wind conditions, an optimal choice, savings in the number of turbines And at a result increase reliability of the system we have.

\section{REFERENCES}

[1] Karki R, Hu P,"Impact of Wind Power Growth on Capacity Credit", Electrical and Computer Engineering, Canadian Conference, 2007.
[2] Pudaruth, G.R.; Furong Li;"Locational Capacity Credit Evaluation", Power Systems, IEEE Transactions on 2009.

[3] Karki R,"Renewable energy credit driven wind power growth for system reliability", Electric Power Systems Research 77 (2007).

[4] Billinton. R., Chen. H:"Effect of windturbine Parameters on the capacity adeguacy of generating systems using wind energy", IEEE Trans.1997 conference on communicatins, power and computing WESCANEX'97 Proceeding; Winnipeg, MB; May 22-23; 1997; pp. 47-52.

[5] Billinton, R., and Li, W.Y.:"Reliability assessment of electrical power systems using Monte Carlo methods".(Plenum press, New York, 1994)

[6] Ezio SESTO,"Wind energy in the world" Renewable Energy 16 (1999) 888-893

[7] Bagen, Billinton. R.,:"Evaluation of different operating strategies in small stand-allone power systems", IEEE Transactions on Energy Convertion, Vol. 20, No. 3, September 2005

[8] R. Billinton, R. N. Allan ,"Reliability Evaluation of Power Systems", 2nd ed. New York and London: Plenum Publishing, 1996.

[9] R. Billinton, S. Kumar, N. Chowdhuary, et.al, "A Reliability Test System for Educational Purposes - Basic Data", IEEE Transactions on Power Systems, Vol. 4, No. 3, 1989, pp. 12381244.

[10] Global Wind Energy Council, www.gwec.net (Oct.2005)

[11] Billinton. R., Chen. H,:"Assessment of Risk-Based capacity benefit factors associated with wind energy convertion systems", IEEE Transactions on power systems, Vol. 13, No. 3,August 1998 